\title{
POLÍTICAS DE FORMAÇÃO DOS PROFISSIONAIS NÃO DOCENTES DA EDUCAÇÃO BÁSICA NO BRASIL: UMA ANÁLISE DO CURSO SUPERIOR DE TECNOLOGIA EM PROCESSOS ESCOLARES
}

\author{
TRAINING POLICY OF NON-TEACHING PROFESSIONALS IN THE \\ BASIC EDUCATION IN BRAZIL: AN ANALYSIS OF THE TECHNOLOGY \\ DEGREE COURSE IN SCHOOL PROCEDURES
}

\author{
Marcondes de Lima Nicácio \\ Doutorando em Educação - PPGE/UFAM, Instituto Federal do Acre - IFAC \\ Cruzeiro do Sul, Acre - Brasil \\ marcondesnicacio@gmail.com \\ José Júlio César do Nascimento Araújo \\ Doutor, Instituto Federal do Acre - IFAC \\ Rio Branco, Acre - Brasil \\ jose.araujo@ifac.edu.br \\ Selma Suely Baçal de Oliveira \\ Doutora, Universidade Federal do Amazonas - UFAM \\ Manaus, Amazonas - Brasil \\ selmabacal@ufam.edu.br
}

\begin{abstract}
Resumo: O artigo apresenta a trajetória do curso superior de Tecnologia em Processos Escolares e constrói reflexões sobre sua proposta de desenvolvimento para o contexto escolar e social. Objetiva-se com a produção referenciar historicamente o curso para compreender como vêm se caracterizando e articulando as realidades das escolas e da sociedade. A pesquisa baseia-se em estudo bibliográfico e documental sobre o tema. O texto demonstra, ao descrever os desafios, o pioneirismo deste curso que constitui a primeira experiência de formação superior de profissionais da Educação Básica para atividades não docentes. Nessa perspectiva, a política de formação de nível superior e interdisciplinar deve ser vista como necessária para qualificar os profissionais que atuam e/ou atuarão na escola. Na conclusão, aponta-se o principal desafio para a construção da qualidade social desse curso, que não pode ser vislumbrado sem a visão da totalidade sócio-histórica e econômica da sociedade atual.
\end{abstract}

Palavras-chave: Políticas de formação. Profissionais da educação. Educação básica. Tecnologia em processos escolares.

Abstract: The article presents the trajectory of the technology degree course in school procedures and constructs reflections on its proposal of development to the social and academic context. It is aimed with the production, referencing historically the course to understand how it has been characterizing and articulating the realities of the schools and the society. The research is based on bibliographic and documental study on the theme. The article demonstrates by describing the challenges, the pioneering of this course which constitutes the first experience of the higher education of professionals of the basic education to non-teaching activities. On that perspective, the training policy of higher and interdisciplinary education must be seen as required to qualify the professionals who act and/or will act in school. At the conclusion, it is pointed out the main challenge to the construction of the social quality of that course, which can't be seen without the total socio-historic and economic view of the actual society.

Keywords: Training policy. Education professionals. Basic education. Technology in school procedures.

Para citar - (ABNT NBR 6023:2018)

NICÁCIO, Marcondes de Lima; ARAÚJO, José Júlio César do Nascimento; OLIVEIRA, Selma Suely Baçal de. Políticas de formação dos profissionais não docentes da educação básica no Brasil: uma análise do curso superior de tecnologia em processos escolares. Eccos - Revista Cientifica, São Paulo, n. 55, p. 1-17, e8572, out./dez. 2020. Disponível em: https://doi.org/10.5585/eccos.n55.8572. 


\section{Introdução}

O Curso Superior de Tecnologia em Processos Escolares é institucionalizado no Brasil em 2010, quando passa a constituir o quadro de formações no Catálogo Nacional dos Cursos Superiores de Tecnologia (CNCST). Uma criação que surge de movimentos reivindicatórios dos funcionários não docentes da educação através da Confederação Nacional dos Trabalhadores em Educação (MEC, 2011).

O Instituto Federal de Educação, Ciência e Tecnologia do Acre (IFAC), no ano de 2011, responsabiliza-se pelo pioneirismo como instituição pública na oferta da formação. As primeiras turmas iniciam o percurso de formação em 2012, nos campi Rio Branco e Cruzeiro do Sul, interfaces do projeto que temos a intenção de discutir, no atendimento às demandas regionais do Juruá1.

No prognóstico da implantação do curso, temos conjuntamente professores, acadêmicos, gestores e organismos sociais ligados à educação discutindo e atuando para fomentar, integrar e fortalecer as identidades e a história do curso, sendo por vezes a instituição não só o espaço de formação acadêmica, mas também de lutas e conquistas para os tecnólogos em processos escolares.

$\mathrm{Na}$ formação, evidenciaram-se realidades e necessidades educativas de espaços e de práticas que se erigiram para atender às nuances do mundo do trabalho no contexto das escolas e para os profissionais não docentes da educação. A natureza multidisciplinar do curso gerou incertezas e ingenuidades na compreensão do poderio gerador das transformações que seriam implementadas, algumas positivas, outras negativas, o que tem repercutido na percepção de escola, educação e sociedade.

A análise no texto é apresentada em quatro partes, sendo inicialmente antecedidas pelo quadro metodológico. A primeira traz o debate sobre a formação de profissionais da escola. A segunda trata da inserção da formação dos profissionais da educação na Rede Federal de Educação Profissional, Científica e Tecnológica, apresentado os elos que explicam a materialidade do curso para os profissionais da educação. A terceira caracteriza o Curso Superior de Processos Escolares do IFAC. E, na quarta parte, na guisa de conclusão, apontamse as transformações e os desafios a ser vencidos pelo próprio curso e a emergência do debate impulsionado pela nova resolução de profissionais da educação, a qual não incluiu o curso de processos escolares. 


\section{Metodologia}

O estudo é uma pesquisa bibliográfica, na qual se buscou apresentar uma discussão contextualizada e histórica do curso de Tecnologia em Processos Escolares que visa formar profissionais para atuar nas escolas. Dessa perspectiva, a pesquisa bibliográfica foi “[...] realizada para fundamentar teoricamente o objeto de estudo, contribuindo com elementos que subsidiam a análise futura dos dados obtidos, [...] imprime sobre eles a teoria, a compreensão crítica do significado neles existente" (LIMA; MIOTO, 2007, p. 44).

Além dessa abordagem, o texto também se vale da pesquisa narrativa como procedimento de análise dos dados e dos fatos que permearam o processo de implantação e de trabalho no curso. Isto se fez necessário porque, como pesquisadores e formadores do curso, nossa análise se materializa na práxis. Assim, assumem-se os pressupostos da pesquisa etnográfica, pois se considera que "o processo de pesquisa se constitui em uma atividade científica básica que, através da indagação e (re)construção da realidade, alimenta a atividade de ensino e a atualiza frente à realidade" (LIMA; MIOTO, 2007, p. 39).

Além disso, utilizou-se a análise de documentos como instrumento de estudo do discurso, partindo dos pressupostos de Cunha (1987, p. 51), para quem a referida análise permite

\footnotetext{
Identificar a cientificidade do discurso através dos procedimentos desta análise, ou seja: como procede o autor/produtor para isolar o seu objeto de análise; como passou de um conjunto de observações dadas a sua interpretação; se contribuiu ou não para a ciência em discussão. [Procede-se] a análise do texto, tentando desmontar a construção do autor/produtor e a Análise Documentária, propriamente dita, visando a identificação das macro-proposições semânticas/traços descritivos/informações "significativas", capazes de traduzir o conteúdo sob a forma de conceitos/palavraschave.
}

Logo, a análise documental busca identificar informações nos documentos, leis, decretos, portarias a partir de questões de interesse do pesquisador, buscando o entrelaçamento de pensamento e ação na reflexão de problemas da vida prática.

\section{O debate sobre a formação de profissionais da escola}

Do ponto de vista da compreensão da realidade pelo prisma marxista, qualquer discussão em torno de políticas educativas deve levar em conta o contexto socioeconômico em que elas foram mediadas e construídas.

No Brasil, a "valorização" do profissional da educação nunca foi vista como prioridade. Isso ocorre porque a relação trabalho x educação x valorização do trabalho é mediada pelos antagonismos que emergem dos conflitos da apropriação do mais valia produzidos pela classe 
trabalhadora. Essa classe de trabalhadores, denominada pelas mais diversas abordagens semânticas no decorre do tempo como: profissionais da educação, funcionários da escola, profissionais não docentes, trabalhador em educação, ainda não conseguiu assegurar os papéis identitários condizentes com o real trabalho que exercem no interior da escola.

Em parte, a problemática está associada à baixa escolarização de acesso ao cargo público destes profissionais, a formação inicial de Ensino Fundamental e Médio e o tipo de função "técnica" e/ou "mecânica", que "acredita-se" que estes profissionais desempenham, corroboram para a desvalorização dos profissionais em todos os sistemas de ensino. Entretanto, é preciso observar que porteiros, merendeiros, auxiliares de biblioteca, secretários escolares juntamente aos novos perfis profissionais participam ativamente da ação educadora da instituição de ensino e esta compreensão é fundamental para que as novas identidades vinguem e promovam a correta e justa valorização desses profissionais.

O reconhecimento profissional do saber formal e informal dos funcionários da escola, já aludido na Lei n ${ }^{\circ}$ 12.014/09, parece não encontrar eco na Emenda Constitucional nº 53/06, a qual, por sua vez, discorre sobre a necessidade do estabelecimento de um piso nacional dos profissionais da educação escolar pública. Essa valorização, seja no âmbito nacional seja nos sistemas estaduais e municipais de ensino, ocorreu para o profissional de magistério, mas não para os profissionais da educação, para os quais o piso nacional ainda é uma incógnita.

Historicamente, como comenta Silva (2016), no PDE (2007), foram criados três programas de formação de profisssionais da escola:

(i) Programa Nacional Escola de Gestores da Educação Básica Pública - o qual qualifica gestores das escolas da Educação Básica pública;

(ii) Profuncionário: Curso Técnico de Formação para Funcionários da Educação, à distância, nível médio, redes públicas estaduais e municipais de Educação Básica, e

(iii) Programa Educação Inclusiva: Direito à Diversidade: para gestores e educadores, sistema educacional inclusivo.

Porém, o PDE (2007) e o PNE (2009) seguem se constituindo para estes profissionais como ganho, pois, como destacam Hillesheim; Garcia (2019), a análise destes documentos demonstra que: 
As proposições identificadas nos documentos consultados vislumbram a disseminação e assimilação de valores e comportamentos alinhados ao modelo de acumulação flexível, bem como a preparação técnica dos trabalhadores com base em conhecimentos operacionais. Este tipo de educação no e pelo trabalho alienado e alienante nega ao trabalhador a construção de saberes que permitam a ele o controle da produção e o avanço em direção a uma nova sociabilidade na qual ele se eduque no e pelo trabalho, como autoatividade que funda e possibilita o desenvolvimento do próprio ser social (HILLESHEIM; GARCIA, 2019, p. 487).

A emenda constitucional n. 53, de 19 de dezembro de 2006, é um dos marcos colaborativos para tal percepção. A expressão que antes nominava "profissionais do ensino" é amplificada pela terminologia "profissionais da educação", o que, em sua natureza, amplia a inclusão dos funcionários não professores na nova redação do art. 206 da CF 88.

Por outro lado, a Lei n. 12.014, de 6 de agosto de 2009, desvela em definitivo esta percepção ao alterar o art. 61 da Lei n= 9.394, de 20 de dezembro de 1996, com a finalidade de discriminar as categorias de trabalhadores que devem ser considerados profissionais da educação. Na conjuntura, são identificadas três categorias de trabalhadores em Educação Básica pública: professores - categoria I; pedagogos - categoria II, e técnicos administrativos categoria III, esta última abarca o enquadramento dos tecnólogos em processos escolares, englobando os profissionais habilitados em áreas pedagógicas ou afins em nível superior.

Já a Lei 12.796, de 04 de abril de 2013, introduziu na LDB o artigo 62-A, pela qual se define a formação inicial dos funcionários técnicos administrativos da educação como de conteúdo técnico-pedagógico, no nível médio e superior, incluindo cursos de pós-graduação.

O PNE, em suas diretrizes, metas e estratégias, ratifica a identidade e a formação inicial dos profissionais da educação, incluindo os funcionários. No caso da Meta 18, algumas das estratégias são:

18.1) Estruturar as redes públicas de educação básica de modo que, até o início do terceiro ano de vigência deste PNE, 90\% (noventa por cento), no mínimo, dos respectivos profissionais do magistério e $50 \%$ (cinquenta por cento), no mínimo, dos respectivos profissionais da educação não docentes sejam ocupantes de cargos de provimento efetivo e estejam em exercício nas redes escolares a que se encontrem vinculados;

18.2) Implantar, nas redes públicas de educação básica e superior, acompanhamento dos profissionais iniciantes, supervisionados por equipe de profissionais experientes, a fim de fundamentar, com base em avaliação documentada, a decisão pela efetivação após o estágio probatório e oferecer, durante esse período, curso de aprofundamento de estudos na área de atuação do (a) professor (a), com destaque para os conteúdos a serem ensinados e as metodologias de ensino de cada disciplina;

Estima-se que 2.732 destes funcionários possuam o Ensino Médio (ASSIS, 2015).

Assim, deve-se considerar que a Meta 18 do Plano Nacional de Educação (Lei no 13.005/14) obriga que a União, os estados, municípios e Distrito Federal garantam planos de carreira e remuneração para os profissionais da educação escolar básica pública, denominação definida 
no artigo 61 da LDB. Logo, é dever do Estado também contruibuir de maneira mais eficiente para incluir formalmente os profissionais formados nos posto de trabalho da escola, bem como articular junto às instituições formadoras ações para qualificar os profissionais existentes.

\section{A inserção da formação dos profissionais da educação na rede federal de educação profissional, científica e tecnológica}

A reestruturação da Rede no governo Lula, iniciada oficialmente em 2005, será a maior, em termos estruturais, pela capilaridade que assumiu em todo país e pela quantidade de investimentos e, sobretudo, pela construção das novas unidades. Porém, como trataremos destas transformações durante todo o trabalho para não se tornar repetitivo, deixaremos que o leitor acompanhe os movimentos e as transformações deste último período no decorrer do texto.

O modelo assumido neste período é o tecnológico-integrado (2004-2013), que, nas estratégias neodesenvolvimentistas, embasam a nova economia política da educação profissional no discurso da essencialidade da educação profissional e tecnológica para contribuir para o progresso socioeconômico, com o foco na justiça social, na equidade, na competitividade econômica e na geração de novas tecnologias (NOGUEIRA, 2016).

A nova legislação, do ponto de vista pedagógico e curricular, além de reaproximar a Educação Profissional do Ensino Médio, rearticulou-se de um modo inédito com a Educação de Jovens e Adultos. Este fato coloca-se como contratendência à elitização, já que, em razão da política nacional de cotas e da implementação do PROEJA, minora os efeitos da tradicional e atual seletividade (LIMA; ZANDONADE, 2014).

No formato como Instituto Federal (IF), é possível perceber os princípios da política que procura aproximar a perspectiva neodesenvolvimentista a neoliberal, tais como: a flexibilidade curricular; a capacidade de diversificação geográfica e pedagógica; o entrelaçamento educação e desenvolvimento, e o papel social da instituição que, no final das contas, se coaduna com os processos mais sofisticados de formação para o mercado.

O curso de Tecnologia em Processos Escolares foi perspectivado como necessidade de formação na segunda edição do CNCST de 2010, se enquadrando no eixo apoio escolar. De modo geral, o perfil de atuação do tecnólogo em processos escolares contemplava uma formação para os processos e as atividades de apoio pedagógico, administrativo, organizacional e de desenvolvimento da ação educativa intra e extraescolar, como discutiremos a seguir. 


\section{O curso superior de tecnologia em processos escolares}

Com a reformulação do CNCST, em 2016, o curso de Processos Escolares agora se enquadra no eixo tecnológico de desenvolvimento educacional e social. Por outro lado, a formação que antes seria concluída em 2400 horas, foi reduzida para apenas 2000 horas.

A complexidade das relações produtivas nos desígnios dos interesses do capital impõese nos processos de formação educacional, aligeirando, e muitas vezes orientando, como deve ser modelada a formação nas instituições escolares. Para Alves (2007, p. 105):

O capital como modo de controle sócio-metabólico é parte intrínseca de todos nós, indivíduos sociais de uma sociedade socializada pelas disposições alienadas da acumulação de valor [...]. O precário mundo do trabalho é um dos sintomas da barbárie social do século XXI.

A realidade material em que tem se consolidado o ensino tecnológico em processos escolares precisa ser refletida dentro da categoria da totalidade para sua compreensão sóciohistórica.

O curso foi pensado e iniciado para 80 alunos de dois polos regionais diferentes, tanto geograficamente como culturalmente, sem considerar ou perceber o que permeia a construção de uma formação profissional, seus interesses e suas contradições. Percebemos no curso, especialmente por seu pioneirismo, os mecanismos do capital como modo de controle sociometabólico, parafraseando Alves (2007). Ao discutir o perfil profissional de conclusão do curso, iniciamos a análise de alguns dos elementos que, a nosso ver, são os mais perceptíveis neste processo:

Planeja, coordena e operacionaliza atividades organizacionais, tecnológicas e gerenciais no âmbito dos espaços educativos. Produz e organiza a oferta de serviços e tecnologias de multimeios para o ensino. Coordena o planejamento da manutenção preventiva e corretiva dos equipamentos escolares, laboratórios e sistemas elétricos e hidrossanitários. Administra almoxarifados e ambientes de segurança alimentar. Planeja, executa, implanta e acompanha processos e fluxos organizacionais escolares. Organiza, supervisiona e executa processos de aquisição, preparo e distribuição da alimentação escolar. Coordena e participa das equipes técnicas de apoio pedagógico e administrativo da escola e da rede de ensino. Coordena e organiza os processos acadêmicos e de conformidade legal da escola. Avalia e emite parecer técnico em sua área de formação (BRASIL, 2016, p. 34).

As bases reprodutivas do capital são reinventadas para perpetuar o controle sobre a classe proletária. A inserção de um perfil de formação, dado por uma complexidade exacerbante, como é a desse profissional, em nossa opinião, é fruto da mão hegemônica.

Olhemos a complexidade e a multiplicidade de ações e atribuições que são depositadas a um único profissional, na perspectiva de uma formação para a atuação flexível, pois esse trabalhador deve planejar, coordenar e operacionalizar. Entendamos o que significa ele pensar, preparar e realizar as atividades de organização, de tecnologia e gerenciais do espaço escolar. 
No que concerne à reflexão sobre concepções de polivalência, Cruz (2012) faz uma análise histórica, mesmo que esteja voltada para avaliar o professor polivalente, que bem serve para a nossa discussão. As similitudes são profícuas, pois são características da mesma classe que os profissionais não docentes pareiam com os docentes, isto é, são todos trabalhadores, independente de categoria.

Nesse prenúncio, Cruz (2012, p. 2897) descreve a conjuntura histórica:

É, pois, sob essa égide descrita que os conceitos de polivalência [...] vão surgir inicialmente no campo educacional brasileiro. Já nos anos 1990 a reforma de Estado e seus desdobramentos nas reformas educativas empreendidas logo após estes conceitos parecem ser ressignificados a partir do processo de restruturação produtiva sob as bases do modelo toytista. Nessas reformas do Estado brasileiro, estarão subjacentes as ideias neoliberais formuladas, em âmbito internacional, para atenderem à reestruturação do capital frente a sua crise, iniciada no final dos anos de $1970 \mathrm{e}$ acentuada no final dos anos de 1980 por meio do desmonte do Estado de Bem-Estar Social.

Desse modo, a polivalência é especialmente sentida no próprio CNCST/2016, quando apresenta o campo de atuação do tecnólogo em processos escolares: "Instituições de educação formal e informal; Organizações não governamentais; Órgãos públicos do sistema de ensino; Institutos e Centros de Pesquisa; Instituições de Ensino, como docente [...]” (BRASIL, 2016, p. 34).

Outro elemento que merece atenção na perspectiva de compreensão conjuntural diz respeito ao modelo de formação assumido para o curso. Mourão (2006), ao construir ilações sobre a fábrica como espaço educativo, nos traz um cenário reflexivo que encaixa-se na concepção de atuação profissional assumida pelo sistema educacional público e privado para como os funcionários técnico-administrativos e que também foi absorvido pelo curso de Processos Escolares. A autora faz uma crítica ao modelo de competência de Zarifian, o qual não considera as condições materiais dos indivíduos. Na era atual, o capital nos obriga a atuar e a ensinar na incerteza. As estratégias de desenvolvimento de competências da organização e de seus trabalhadores são formas sutis de controle do conflito entre capital e trabalho.

Mourão (2006, p. 27) acrescenta ainda que o sistema capitalista perspectiva um conceito e uma manifestação de competência em que se tenham "relações de trabalho flexíveis e autônomas - conhecimento de todo o processo de produção, superando a dicotomia pensar/fazer".

No caso do curso, foram reunidos profissionais de múltiplas áreas: pedagogos, administradores, economistas, profissionais de tecnologia da informação (TI), licenciados em Letras e em outras Ciências Humanas, além de técnicos administrativos da instituição, para dar vida a um modelo de formação desconhecido por todos. O que foi agravado pela equivoca 
postura assumida pela instituição ao estabelecer um paradigma único para todas as diferentes realidades iminentes nos campi do IFAC.

Pela portaria IFAC n. 1.062, de 5 de agosto de 2014, instituiu-se, assim como em 2011, uma comissão multicampi para (re)elaborar o Projeto Pedagógico do Curso Superior de Tecnologia em Processos Escolares. As reuniões de ambos os momentos serviram para aguçar as divergências de concepções na formação e na compreensão desse profissional. De forma muito explícita, tivemos uma espécie de luta de áreas entre os professores formadores no sentido de imporem suas percepções e visões de homem, de escola e de sociedade.

Como resultado deste processo, Assis (2015, p. 36), em relatório produzido para o Projeto CNE/UNESCO - 914BRZ1144. 3 - Desenvolvimento, aprimoramento e consolidação de uma educação nacional de qualidade, nos diz, ao analisar o PPC do curso de processos escolares, que:

\begin{abstract}
Analisando-se as Ementas das disciplinas ofertadas no curso, observou-se que três delas, da área de gestão escolar apresentam um conteúdo fortemente voltado para a realidade empresarial, sobretudo do setor privado, propondo conteúdos que remetem aos princípios do setor produtivo empresarial, estimulando a competitividade e o individualismo, contradizendo os princípios destacados no PPC e pelas demais disciplinas do curso. São elas 'Empreendedorismo e Inovação', 'Planejamento Estratégico e Gestão por Resultados' e 'Fundamento da Gestão de Pessoas'.
\end{abstract}

Além disso, uma construção tão importante, arraigada de conexões políticas, sociais, econômicas e culturais, como é a edificação de um curso e de uma profissão, não pode ser privilégio de poucos, uma vez que envolve interesses de muitos. Os tecnólogos em Processos Escolares apresentam habilitação adequada para atuar nas instituições de ensino, por isso, a profissão necessita ser incluída nos planos de carreiras da educação, já que contribuirá para a qualidade da educação escolar. Nos dados da tabela 1, apresentamos as informações sobre os profissionais que exercem funções técnico-administrativas nas escolas do Estado do Acre, com escolaridade entre o Ensino Fundamental e Médio:

Tabela 01 - Número de FTA, por estado e por esfera administrativa

\begin{tabular}{c|c|c|c|c}
\hline Estado & Federal & Estadual & Municipal & Total \\
\hline Acre & 180 & 7.420 & 6.207 & 13.807 \\
\hline
\end{tabular}

Fonte: Assis, 2015, p.38 com Dados Censo Escolar, 2013 (Adaptado).

A consolidação do curso está na relevância e na importância dos próprios trabalhadores não docentes da educação para a expansão do ensino público e gratuito e sua oferta de qualidade. Todos os profissionais em suas diferentes áreas de apoio ao ensino são extremamente indispensáveis, portanto, devem ser valorizados, pois reconhecê-los é também valorizar sua formação. 
Porém, é perceptível, considerando os dados da oferta em Cruzeiro do Sul-Acre (Tabela 02), a falta de reconhecimento e de desenvolvimento do profissional de Tecnologia em Processos Escolares. Como reflexo, tem-se um impacto nos números de abandono, conclusão e desligamento em comparação ao número inicial de matrícula de cada turma.

Tabela 02 - Ciclo de matrícula do curso superior de tecnologia em processos escolares campus cruzeiro do Sul - 2012-2020

\begin{tabular}{c|c|c|c|c|c|c|c}
\hline \multirow{2}{*}{$\begin{array}{c}\text { Turma/Ano } \\
\text { de ingresso }\end{array}$} & $\begin{array}{c}\mathbf{N}^{\mathbf{0}} \\
\text { Matrícula }\end{array}$ & Abandono & Concluído & Integralizado & Desligado & $\begin{array}{c}\text { Em } \\
\text { Curso }\end{array}$ & $\begin{array}{c}\text { Transf. } \\
\text { Externa }\end{array}$ \\
\cline { 3 - 8 } & 39 & 17 & 22 & - & - & - & - \\
\hline 2012 & 40 & 19 & 20 & 1 & - & - & - \\
\hline 2013 & 40 & 14 & 19 & 1 & 5 & 1 & - \\
\hline 2014 & 40 & 10 & 22 & 1 & 2 & 5 & - \\
\hline 2015 & 38 & 9 & $*$ & $*$ & 3 & 26 & - \\
\hline 2016 & 41 & 13 & $*$ & $*$ & 10 & 17 & 1 \\
\hline 2017 & 40 & 16 & $*$ & $*$ & 2 & 22 & - \\
\hline 2018 & 40 & 2 & $*$ & $*$ & 4 & 33 & 1 \\
\hline 2019 & 40 & - & $*$ & $*$ & 2 & 38 & - \\
\hline 2020 & & & & & $*$ & & \\
\hline
\end{tabular}

Nota: * Dados cujo ciclo nos status de conclusão e na integralização ainda está em andamento. Fonte: MEC -SisTEc - 2020, organização dos autores.

A oferta anual ao final do ciclo acaba por formar apenas uma média de $50 \%$ do total dos ingressantes e, no decorrer dos anos, a taxa de desligamento do curso tem variado entre $12,5 \%$ a $25 \%$. Além disso, os percentuais de abandono também são altíssimos, chegando até a $47,5 \%$.

Neste sentido, a coordenação do curso enviou um documento ao Executivo Municipal com o objetivo de que acontecesse a criação do cargo e a inserção destes profissionais no plano de carreiras dos servidores públicos municipais de Cruzeiro do Sul. No expediente, destacou-se que "a implantação do curso justifica-se, devido à necessidade de aperfeiçoamento e desenvolvimento dos profissionais encarregados pelos trabalhos nos diversos espaços educativos" (IFAC, 2017, p. 2). E ainda que com a formação de Tecnólogos em Processos Escolares, haveria uma adequada preparação da mão de obra encarregada dos diversos processos necessários à melhoria qualidade da educação.

O tecnólogo em Processos Escolares, formado pelo IFAC, deve apresentar um perfil que o habilite a realizar atividades voltadas para estabelecer constantemente o aprimoramento dos processos, práticas e atividades escolares. E, nesse escopo, é importante considerarmos que sua formação profissional deve dialogar com as tranformações sociais, científicas e tecnológicas atuais. Por isso, na próxima parte, mostramos os desafios e as transformações que ainda estão por vir. 


\section{As transformações que ainda estão por vir, a guisa de conclusão}

O Conselho Nacional de Educação (CNE), ao publicar a Resolução n. 2, de 13 de maio de 2016, definiu as Diretrizes Curriculares Nacionais para a Formação Inicial e Continuada em Nível Superior para Funcionários da Educação Básica, impactando a formação em processos escolares.

O documento apresenta outro momento da história para o curso. A nova configuração foi acolhida pelos profissionais que conduzem a formação pela gestão institucional e pelos acadêmicos em formação, com um misto de temor e dúvidas. Temor por estarmos ainda em um processo de construção das identidades do curso, um processo de ascensão, que a nosso ver parece ter se esfacelado. Pois, a multidisciplinaridade e seus diversos interlocutores, nos dois últimos anos, na experiência em questão, pareciam começar a compreender a natureza e a importância da formação e, por conseguinte, a construir um diálogo, mediado pelos erros e acertos da formação de 4 turmas já egressas.

A resolução, ao definir em seu quarto capítulo a formação inicial dos funcionários da Educação Básica em nível superior, nos fez perder de vista nossa perspectiva de formação, à medida que deu nova configuração aos cursos de formação inicial para tais profissionais. Já no artigo $9^{\circ}$ colocou uma nova organização:

I - Curso Superior de Tecnologia em Educação e Processos de Trabalho: Secretaria Escolar;

II - Curso Superior de Tecnologia em Educação e Processos de Trabalho: Alimentação Escolar;

III - Curso Superior de Tecnologia em Educação e Processos de Trabalho: Infraestrutura Escolar;

IV - Curso Superior de Tecnologia em Educação e Processos de Trabalho: Multimeios Didáticos (CNTE, 2016, p. 31).

As dúvidas geradas pela resolução também diz respeito à forma como o documento, o qual tem por objetivo estabelecer diretrizes de formação, foge de seu escopo ao estabelecer competências e atribuições na valorização dos funcionários da Educação Básica. Consideramos que a bandeira de valorização dos trabalhadores deve ser assumida por todos, e não ser direcionada para os espaços de formação dos profissionais.

Em documento institucional, externamos ao CNE nossas dúvidas. Sendo as principais:

1. Há necessidade de extinção do Curso Superior de Tecnologia Processos Escolares?

2. O curso de Tecnologia em Processos Escolares deve-se adequar-se ao formato dos cursos previstos no art. 13? Ou devemos substituir por outro?

3. Como estes cursos deverão ser organizados? Pois, segundo a resolução: O caráter interdisciplinar considera a oferta das quatros áreas/ cursos: Secretaria Escolar, Alimentação Escolar, Infraestrutura Escolar e Multimeios Didáticos?

4. Do que trata a resolução quando orientam que as IES devem garantir a base comum nacional das orientações curriculares? (IFAC, 2017, p. 1-2). 
Ao apresentar as preocupações, falamos do pioneiro nesta oferta educacional na esfera pública e das experiências construídas com os tecnólogos em Processos Escolares e entre nós, os formadores. Neste sentido, vemos elencados os seguintes desafios:

I Reconhecimento do curso como legítimo na formação de profissionais não docentes para atuar na escola;

II Reconhecimento da profissão e sua inclusão nos Planos de Carreiras, Cargos e Salários do Magistério;

III Construção das identidades do curso;

IV Valorização e qualidade socialmente referenciada desta formação;

V Discursão aberta sobre o caráter generalista do curso e sua possível adaptação nas áreas de formação, e

VI Estabelecimento do cargo e sua definição junto às secretarias estaduais e municipais de educação, estabelecimento de ensino privado e outros espaços de trabalho sobre as competências desejáveis para profissão.

A revolução que ainda está por vir deve ser iniciada pela criação de espaços de debates que discutam a própria atuação do profissional no contexto local e global.

Como alternativa para a construção das identidades dos profissionais de processos escolares, temos insistido na construção de espaço de debates e na organização de um movimento em que sejam agregados acadêmicos, egressos, professores formadores e o poder público para a edificação de políticas atinentes às necessidades da categoria frente às demandas urgentes de qualidade social da educação.

Tais levantes nem de longe podem ser conduzidos sem a compreensão da totalidade social em questão. Daí nossa preocupação em construir um movimento que produza identidades, sem perder de vista que a inserção dos profissionais em políticas que os beneficiem não desvela ou diminui a luta maior com que devemos estar comprometidos. Um movimento caracterizado por uma revolução socioeconômica que nos permitirá reconstruir a sociedade com predomínio de equidade e justiça social.

Já podemos apresentar alguns avanços para esses profissionais. Dentre eles, as audiências públicas para discutir a atuação dos profissionais não docentes da educação, resultando na aprovação da legislação o que, no âmbito de Cruzeiro do Sul, cria o dia dos profissionais de Tecnologia em Processos Escolares. A Lei Municipal n. 764, de 30 de outubro de 2017, representa um passo inicial para inserção e reconhecimento da profissão.

Para tanto, não podemos esquecer que o curso superior de Tecnologia em Processos Escolares se pauta nos seguintes objetivos: Formar profissionais responsáveis por processos 
acadêmicos e fluxos organizacionais; Atuar na organização de espaços educativos; Formar cidadãos éticos; Promover, orientar e administrar as atividades de apoio pedagógico e administrativas; Fomentar projetos e ações da educação, e Contribuir para a melhoria dos espaços escolares.

Os objetivos em questão precisam ser (re)pensados, não esquecendo o fim maior que ao nosso ver representa seu ideal de existência: a construção de uma educação pública com qualidade social.

O tecnólogo em Processos Escolares deve apresentar um perfil que o habilite a realizar atividades voltadas para estabelecer constantemente o aprimoramento dos processos, das práticas e das atividades escolares. E, nesse escopo, é importante considerarmos que sua formação profissional deve dialogar com as tranformações sociais, científicas e tecnológicas atuais, sem perder de vista que, "numa proposta de âmbito nacional é necessário cuidar para que as funções exercidas na escola no âmbito dos funcionários sejam contempladas, sob o risco de contribuir para reforçar as hierarquias já existentes entre os diversos segmentos de funcionários na escola" (ASSIS, 2015, p. 37).

Destarte, o curso oferecido no IFAC - Campus Cruzeiro do Sul, aprovado pelo MEC pela Portaria n. 891 de 29 de dezembro de 2016, já formou, desde sua implantação, em 2012, quatro turmas e 5 turmas estão em processo de formação, em uma média de 66 profissionais já formados que precisam ser inseridos nos constextos socioescolar e do trabalho na educação.

Enquanto instituição, precisamos estar comprometidos com a formação social, profissional e política, em um ciclo dinâmico e, por outro lado, cabe ao poder público contribuir para que os mesmos sejam aproveitados a fim de que colaborem com a melhoria da educação ofertada à população.

\section{Notas:}

1. Região da divisão territorial do Estado do Acre - Brasil, que abrange os municípios de Cruzeiro do Sul, Mâncio Lima, Marechal Thaumaturgo, Porto Walter e Rodrigues Alves, em área territorial de 3.194.472,80 hectares, $19,46 \%$ de participação na área do Estado.

2. Relata Bryan (2008, p.44) que no interior da fábrica o trabalhador menor fazia o mesmo trabalho do homem, a redução de jornada de trabalho para dedicar ao estudo no interior da fábrica não era desejo de nenhum empresário, que eram contrários inclusive às férias. Considerado o trabalho operário como de natureza estritamente manual e leve, não demando "concurso de um cérebro educado". Por isso, o empresariado em nenhum momento deste período sugeriu atividades escolares como forma desejável de ocupação do tempo livre previsto em lei. 


\section{Referências}

ALVES, G. Dimensões da Reestruturação Produtiva: ensaios de sociologia do trabalho. 2. ed. Londrina: Práxis; Bauru: Canal 6, 2007.

ARAÚJO FILHO, H. M. G. As lutas e a agenda sindical para a valorização do magistério na perspectiva da CNTE: qual a contribuição do novo plano nacional de educação? Cad. Cedes, Campinas, v. 35, n. 97, p. 575-587, set./dez. 2015. Disponível em: http://www.scielo.br/pdf/ccedes/v35n97/1678-7110-ccedes-35-97-00575.pdf. Acesso em: 12 nov. 2017.

ASSIS, L. M. Documento técnico contendo diagnóstico das iniciativas de formação inicial, em nível superior, e formação continuada dos profissionais da Educação Básica (funcionário e técnico administrativo) efetivadas pelas IES, especialmente as Universidades Públicas e Institutos Federais. Brasília: CNE/MEC, 2015. Disponível em:

http://portal.mec.gov.br/index.php?option=com_docman\&view=download\&alias=26091 diagnostico-iniciativas-formacao-inicial-continuada-profissionais-edfisica-basicapdf\&Itemid=30192. Acesso em: 05 nov. 2017.

BRASIL. Constituição (1988): Constituição da República Federativa do Brasil: texto constitucional promulgado em 5 de outubro de 1988, com as alterações determinadas pelas Emendas Constitucionais de Revisão nos 1 a 6/94, pelas Emendas Constitucionaisnos 1/92 a 96/2017 e pelo Decreto Legislativo no 186/2008. Brasília: Senado Federal, Coordenação de Edições Técnicas: 2017.

BRASIL. Lei 11.892, de 29 de dezembro de 2008. Institui a Rede Federal de Educação Profissional, Científica e Tecnológica, cria os Institutos Federais de Educação, Ciência e Tecnologia, e dá outras providências. Diário Oficial da União, Brasília, Seção 1, v.145, n. 253, p. 1, 30 dez. 2008.

BRASIL. Lei 13.005 de 25 de junho de 2014. Aprova o plano nacional de educação - PNE e dá outras providências. Diário Oficial da União, Brasília, v. 151, n. 120-A, p. 1, 26 jun. 2014.

BRASIL. Lei n. 12.014 de 6 de agosto de 2009. Altera o art. 61 da Lei ${ }^{\circ} 9.394$, de 20 de dezembro de 1996, com a finalidade de discriminar as categorias de trabalhadores que se devem considerar profissionais da educação. Diário Oficial da União, Brasília, v. 146, n. 150, p.1, 7 de ago. 2009.

BRASIL. Lei n. 12.796 de 4 de abril de 2013. Altera a Lei no 9.394, de 20 de dezembro de 1996, que estabelece as diretrizes e bases da educação nacional, para dispor sobre a formação dos profissionais da educação e dar outras providências. Diário Oficial da União, Brasília, v. 150, n. 65 , p. 1, 5 abr. 2013.

BRASIL. Ministério da Educação. Catálogo Nacional dos Cursos Superiores de Tecnologia. 3. ed. Brasília: MEC, 2016.

BRASIL. Ministério da Educação. Portaria No 891, de 29 de dezembro de 2016. Diário Oficial da União, Brasília, a. 153, n. 251, p. 206-207, 30 dez. 2016. 
BRYAN, N. A. P. Educação, processo de trabalho, desenvolvimento econômico: contribuições ao estudo das origens e desenvolvimento da formação profissional no Brasil. Campinas: Alínea, 2008.

CNTE. Funcionário da Educação: Conquista e desafios da formação e da valorização profissional. Brasília: CNTE, 2016. Disponível em: <

https://www.cnte.org.br/images/stories/2016/cartilha_formacao_funcionarios_final_web_3.pd f>. Acesso em: 17 out. 2017.

CRUZ, S. P. S. Concepções de Polivalência e Professor Polivalente: Uma análise históricoLegal. In: IX Seminário Nacional de Estudos e Pesquisas "História, Sociedade e Educação no Brasil”, 2012, João Pessoa. Anais eletrônicos, João Pessoa: HISTEDBR, 2012. p. 2895 2908. Disponível em: < http://www.histedbr.fe.unicamp.br/acer_histedbr/seminario/seminario9/PDFs/3.61.pdf>. Acesso em: 17 out. 2017.

CUNHA, Isabel M. R. Ferin. Análise documentária. In: SMIT, Johanna W (org.) Análise documentária: a análise da síntese. Brasília: IBICT, 1987. p. 38-60.

CUNHA, L. A. O ensino de ofícios nos primórdios da industrialização. São Paulo: UNESP, Brasília: FLASCO, 2005.

FONSECA, C. S. História do Ensino Industrial no Brasil. Rio de janeiro: Escola Técnica, 1961.

GERMANO, J. W. O Estado Militar no Brasil (1964-1985): um estudo sobre a política educacional. 1900. 444 f. Tese, Doutorado em Educação, Universidade Estadual de Campinas, Campinas, 1990.

HILLESHEIM, Jaime; GARCIA, Adir Valdemar. Educação e trabalho no Brasil: a perspectiva defendida pelo capital para a formação dos trabalhadores. Rev. katálysis, Florianópolis, v. 22, n. 3, p. 491-501, Sept. 2019. Disponível em: http://www.scielo.br/scielo.php?script=sci_arttext\&pid=S141449802019000300491\&lng=en $\&$ nrm=iso. Acesso em: 06 nov. 2020.

IFAC. Coordenação do Curso Superior de Processos Escolares. Proposta para inserção do curso Superior de Tecnologia em Processos Escolares no plano de carreira da educação do município de Cruzeiro do Sul-Acre. Cruzeiro do Sul, 20 out. 2017. Disponível em: https://mail.google.com/mail/u/0/?tab=wm\#search/mirna/15f3b52963226b6d. Acesso em: 12 nov. 2017.

IFAC. Direção de Ensino, Pesquisa e Extensão - Campus Cruzeiro do Sul. Ofício $n^{o}$ 01/2017/ IFAC /Campus Cruzeiro do Sul-AC/ Direção de Ensino. Cruzeiro do Sul, 24 jul. 2017. Disponível em: https://mail.google.com/mail/u/0/?tab=wm\#search/mirna/15f3b52963226b6d. Acesso em: 12 nov. 2017.

KUENZER, A. A reforma do ensino técnico no Brasil e suas consequências. In: FERRETI, C. J.; SILVA JUNIOR, J. R.; OLIVEIRA, M. R. N. (Orgs.). Trabalho, formação e currículo: para onde vai a escola? São Paulo: Xamã, 1999. 
LDB: Lei de diretrizes e bases da educação nacional. Brasília: Senado Federal, Coordenação de Edições Técnicas, 2017.

LIMA, M. O desenvolvimento do tempo socialmente necessário para a formação profissional. Vitória: Autor, 2010.

LIMA, M; ZANDONADE, V. Metamorfose da Rede Federal da Educação Profissional no Brasil: expansão, diversificação, mercantilização e flexibilidade. Minas Gerais. In: Seminário Nacional de Educação Profissional e Tecnológica, 2014, Belo Horizonte. Anais do IV SENEPT: Belo Horizonte: CEFET-MG, 2014. Disponível em: http://www.senept.cefetmg.br/galerias/Anais_2014/GT03/GT_038_x.PDf. Acesso em: 20 jan. 2015.

LIMA, T. C. S.; MIOTO, R. C. T. Procedimentos metodológicos na construção do conhecimento científico: a pesquisa bibliográfica. Rev. Katálysis [online]. vol.10, n.spe, pp.37-45, 2007. ISSN 1982-0259. Disponível em: http://dx.doi.org/10.1590/S141449802007000300004 . Acesso em: 30 nov. 2017.

LIMA, Marcelo; ZANDONADE, Viviane. Metamorfose da Rede Federal da Educação Profissional no Brasil: expansão, diversificação, mercantilização e flexibilidade. Minas Gerais, Anais do IV SENEPT, 2014. Disponível em: http://www.senept.cefetmg.br/galerias/Anais_2014/GT03/GT_038_x.PDF. Acesso em: 12 nov. 2020.

MEC. Primeiro curso de tecnologia em processos escolares é lançado. 07 jun. 2011. Disponível em:http://portal.mec.gov.br/ultimas-noticias/209-564834057/16721-primeiro-curso-detecnologia-em-processos-escolares-e-lancado . Acesso em: 17 out. 2017.

MEC-SISTEC - SISTEMA DE INFORMAÇÕES DA EDUCAÇÃO PROFISSIONAL E TECNOLÓGICA. Ciclo de Matrícula - Processos Escolares. Disponível em: sistec.mec.gov.br.imprimir/index. Acesso em: 6 nov. 2018.

MÉSZÁROS, I. Estrutura social e formas de consciência: a determinação social do método. Tradução de Lucina Pudenzi, Francisco Raul Cornejo, Paulo Cezar Castanheira. São Paulo: Boitempo, 2009.

MOTA, A. E.; AMARAL, A. S. Reestruturação do capital, fragmentação do trabalho e Serviço Social. In: MOTA, A. E. (org.). A nova fábrica de consensos. São Paulo: Cortez, 1998.

MOURÃO, A. R. B. A fábrica como espaço educativo. São Paulo: Scortecci, 2006.

NOGUEIRA, Silvia C. C. II Fase da política de expansão da Rede Federal de Educação Profissional e Tecnológica no Amazonas: acesso ampliado e precarizado à educação pública. 2016. 210 f. Tese, Doutorado em Educação, Faculdade de Educação, Universidade Federal do Amazonas, Manaus, 2016.

SILVA, Andréa Villela Mafra da. Políticas Educacionais no Brasil: a Articulação entre as Tecnologias, o Tecnicismo e a Pedagogia de Resultados. Cadernos de Pesquisa: Pensamento 
Educacional, Curitiba, v. 11, n. 27, p.219-238 jan./abr. 2016. Disponível em https://utp.br/cadernos_de_pesquisa/. Acesso em: 05 de nov. 2020. 